\title{
Pregnancy Outcome between Booked and Unbooked Cases in A Tertiary Level Hospital
}

\author{
Adhikary $A^{1}$, Begum $A^{2}$, Joty FS ${ }^{3}$, Sarker NR ${ }^{4}$, Akhter T ${ }^{5}$
}

Conflict of Interest: None

Received: $16-10-2017$

Accepted: $12-11-2017$

www.banglajol.info/index.php/JSSMC

Key Words:

Booked case, Unbooked case, Conclusion: The study showed a positive correlation between socio-demographic factor and lack antenatal care, Fetomaternal of proper antenatal care and adverse pregnancy outcome. Improving the availability and accessibility out come

\begin{abstract}
To achieve the Sustainable Development Goals (SDG'2030) with regards to maternal health, there is need for research on the local causes and factors influencing adverse maternal \& foetal outcomes in health institutions. Antenatal care throughout the pregnancy can ensure better feto-maternal outcome. It also contributed to reduction of maternal and infant mortality. This study was an attempt to enable health care providers to know where to focus to overcome adverse maternal outcome.
\end{abstract}

objectives: To find out the difference in maternal and perinatal outcome and socio-demographic characteristics in booked and unbooked cases. Design: A Cross-sectional observational study.

Place of study :Department of Obststrics and Gynaeology, Shaheed Suhrawardy Medical College Hospital.

Study period: April'2015 to july'2015. Study population- All patients admitted for delivery and puerperium during study period.

Results: Unbooked mothers constituted $39.1 \%$ of the 218 deliveries in the studied period. There was no mean age difference between booked mothers and unbooked mothers (26.05 5.5 and 25.44 $\pm 5.4 ; P=0.667)$. But unbooked cases had a lower educational status $(P<0.0036)$. Majority of the unbooked cases were from low family income group. Unbooked mothers were about less likely to deliver by spontaneous vaginal delivery compared to booked mothers $(28 \%$ to $39 \%$; $P<0.339)$ and more likely to be delivered by emergency caesarean section than booked mothers. Unbooked mothers were having low birth weight babies than booked mother $(2.65 \pm 0.595$ and $3.02 \pm 0.477, p<0.010)$. Referral to neonatal unit more common in unbooked cases $(69.6 \%$ to 25.6\%). Post partum complications in unbooked and booked cases were (44\%and 20.5\%).

of quality antenatal and delivery care services in all our institutes will improve pregnancy outcome.

[J Shaheed Suhrawardy Med Coll 2017; 9(2): 43-48] DOI: http://dx.doi.org/10.3329/jssmc.v9i2.37261

\section{Introduction:}

Childbirth is a natural and physiological event. Though it acts as a rewarding event for majority of couples, yet it may turn out into a nightmare by an unforeseen complication.

Bangladesh is one of the developing countries with high maternal and neonatal mortality rates.

1. Dr. Alpana Adhikary, Associate Professor, Department of Gynae \& Obs., Shaheed Suhrawardi Medical College Hospital

2. Dr. Anwara Begum, Associate Professor, Department of Gynae \& Obs., Dhaka Medical College Hospital

3. Dr. Fahmida Sharmin Joty, Assistant Professor, Department of Gynae \& Obs., Care Medical College Hospital

4. Dr. Nihar Ranjan Sarker, Associate professor, Dept of Paediatrics, Shaheed Suhrawardi Medical College Hospital

5. Dr. Tahmina Akhter, Medical officer, Department of Virology, BSMMU, Dhaka

Correspondence to: Dr. Alpana Adhikary, Associate Professor, Department of Gynae \& Obs, Shaheed Suhrawardi Medical College Hospital, alpanaadhikary@gmail.com
Maternal mortality ratio in developing countries in 2015 is 239 per 100000 live births in developing countries versus 12 per 100000 live births in developed countries (WHO’2018) ${ }^{1}$.

Though maternal mortality ratio in Bangladesh is 176 per 100000 live births which is still much higher than other countries $^{2}$. The health care system aiming to reduce morbidity and mortality related to pregnancy is focus on maternal and newborn health. The health care that a woman receives during pregnancy, at the time of delivery, and soon after delivery is important for the survival and wellbeing of both the mother and the child. The government of Bangladesh is committed to achieving Sustainable Development Goal (SDG) by 2030, to improve maternal health, by reducing the maternal mortality ratio from 176 to 70 deaths per 100.000 live births by 2030 (UNDP, 2015) ${ }^{1}$. The SDG Goal 3 for Bangladesh has been set also to reduce 
the under-5 mortality ratio from 30 to 12 per 1,000 live births in by $2030^{2}$. Accordingly, the Ministry of Health and Family Welfare has developed various policies and strategies to improve maternal and newborn health. To achieve sustainable Development Goals (SDG) with regards to maternal health, there is need for research on the local causes and factors influencing adverse maternal outcomes in individual institutes.

Antenatal care is systemic supervision of pregnant women and aims to improve feto-maternal outcome. World health Organization has specific guideline for a pregnant woman should have at least 4 antenatal visits during pregnancy period $^{3}$. Maternal complications and poor perinatal outcome are highly associated with non-utilization of antenatal care and delivery care services provided by the health care centers. During 2010-2015, the ANC coverage, defined as the percentage of women aged 15-49 years who attended at least one ANC visit with a skilled provider, was around $85 \%$ globally and approximately $77 \%$ in the least developed countries ${ }^{4,5}$

But in Bangladesh the percentage of women who seek antenatal care at least once in their entire pregnancy period is $64 \%$ in whereas only $31 \%$ have more than four antenatal visits ${ }^{3}$.

The reason for poor utilization of health care facilities in Bangladesh is a matter of concern as many unbooked mothers are seen with dreaded maternal complications and adverse neonatal outcome. Though much stress has been put by our Government to reduce the complications of maternal and child health by proper utilization of antenatal care but the uptake of present services is far from universal even in settings where they are readily available.

With this impression, this study is planned to explore relationship between the socio demographic characteristics of booked and unbooked cases with maternal and perinatal outcomes in a tertiary level hospital where antenatal, intranatal \& postnatal care are well provided.

\section{Methodology}

This Cross-sectional observational study carried out among patients admitted for delivery and puerperium in labour ward in the Department of Obststrics and Gynaeology, Shaheed Suhrawardy Medical College Hospital from April 2015 to July 2015. All women admitted for delivery, irrespective of age, gestational age, parity, booking status and patients discharged and readmitted with any complication during puerperium were included in this study. Pregnant woman admitted for any complication and treated for without delivery of the foetus were excluded from the study.

Non-probability/Purposive sampling was done from the study population. Patients were selected through short interview applying inclusion and exclusion criteria. No more than 218 subjects were feasible to be included in the study during the study period. A structured questionnaire was designed including all the variables of interest

Data was collected through direct interview of the patients at the respective departments by the researcher and competent colleagues. Detailed history and Pregnancy outcome of patients were recorded on questionnaire. Antenatal booking record was reviewed. Patients were divided into 2 groups i.e., Booked and Unbooked.

Booked' patients were those who carried documented evidence of more than or equal to 4 antenatal visits. Those who did not fulfill these criteria were labeled as 'Unbooked' patients.

Collected data was checked and edited first. Then they were processed with the help of software SPSS (Statistical Package for Social Sciences) version 16 and analyzed. The test statistics used to analysis the data were descriptive statistics, Pearson Chi-Square test. For all analytical tests level of significance was set at 0.05 and $p<0.05$ was considered significant.

\section{Results:}

A total of 218 patients who fulfilled the inclusion criteria were participated in the study.

Among 218 cases $60.9 \%$ were booked cases and 39.1\% were unbooked cases.

Table 1

Distribution of patients according to having Ante natal care $(n=218)$

\begin{tabular}{lccc}
$\begin{array}{l}\text { Having } \\
\text { antenatal care }\end{array}$ & Frequency & Percent & $\begin{array}{r}\text { Commulative } \\
\text { Percentage }\end{array}$ \\
\hline Booked cases & 133 & 60.9 & 60.9 \\
Unbooked cases & 85 & 39.1 & 39.1 \\
\hline & 218 & 100.0 & \\
\hline
\end{tabular}

Table II

\begin{tabular}{|c|c|c|c|c|c|}
\hline \multicolumn{6}{|c|}{ Comparison of Mean age (years) between booked and unbooked cases $(n=218)$} \\
\hline & No & Mean & Std. deviation & Std. Error Mean & $\mathrm{T}$ test \\
\hline Booked cases & 133 & 26.05 & 5.591 & .895 & 0.667 \\
\hline Unbooked cases & 85 & 25.44 & 5.409 & 1.082 & \\
\hline
\end{tabular}


Among 218 cases Mean ages of booked and unbooked cases were $26.05 \pm 5.5$ and $25.44 \pm 5.4$. $P$ value is more than 0.05 which is not significant.

Table III shows the comparison of educational status between booked and unbooked cases. Regarding 218 of booked and unbooked cases, primary education level are same between two group, Higher secondary78.9\%and graduation and above are $87.5 \%$ in boked cases. Pearson Chi-Square test was done. $\mathrm{P}$ value is $<0.05$, which is significant.

Table-III

Comparison of educational status between booked and unbooked cases $(n=218)$

\begin{tabular}{|c|c|c|c|c|c|c|c|}
\hline \multirow[t]{2}{*}{ Educational Status } & \multicolumn{2}{|c|}{ Booked cases } & \multicolumn{2}{|c|}{ Unbooked cases } & \multicolumn{2}{|c|}{ Total } & \multirow[t]{2}{*}{$\mathrm{P}$ value } \\
\hline & No & $\%$ & No & $\%$ & No & $\%$ & \\
\hline Primary & 27 & 50.0 & 27 & 50.0 & 54 & 100.0 & \\
\hline Secondary & 29 & 42.9 & 42 & 57.1 & 71 & 100.0 & 0.0036 \\
\hline HigherSecondary & 53 & 78.9 & 12 & 21.1 & 65 & 100.0 & \\
\hline Graduation and higher & 24 & 87.5 & 4 & 12.5 & 28 & 100.0 & \\
\hline Total & 133 & 60.9 & 85 & 39.1 & 218 & 100.0 & \\
\hline
\end{tabular}

Table-IV

Comparison of Family income between booked and unbooked cases $(n=218)$

\begin{tabular}{|c|c|c|c|c|c|c|c|}
\hline \multirow[t]{2}{*}{ Cases } & & \multicolumn{2}{|c|}{ Family income } & \multirow[b]{2}{*}{ 12100-15000tk } & \multirow[b]{2}{*}{$>15000 \mathrm{tk}$} & \multirow[t]{2}{*}{ Total } & \multirow[t]{2}{*}{$\mathrm{P}$ value } \\
\hline & & $<8000$ tk & $8100-12000 t k$ & & & & \\
\hline \multirow{2}{*}{ Booked cases } & no & 7 & 48 & 41 & 37 & 133 & \\
\hline & $\%$ & $5.1 \%$ & $36.04 \%$ & $39.82 \%$ & $27.8 \%$ & $100 \%$ & \\
\hline \multirow[t]{2}{*}{ Unbooked cases } & no & 10 & 48 & 24 & 3 & 85 & 0.053 \\
\hline & $\%$ & $12 \%$ & $56 \%$ & $28 \%$ & $4 \%$ & $100 \%$ & \\
\hline \multirow[t]{2}{*}{ Total } & no & 17 & 96 & 65 & 40 & 218 & \\
\hline & $\%$ & $7.8 \%$ & $43.8 \%$ & $29.7 \%$ & $18.8 \%$ & $100 \%$ & \\
\hline
\end{tabular}

Among booked cases $28.2 \%$ patient's family income more than 15000 Tk but in unbooked cases only $4 \%$.There is no difference in 8100-12000tk group. Pearson Chi-Square test was done .

$P$ value is $>0.05$.

Table 5 shows among 218 cases vaginal delivery $34.4 \%$ and caesarean section $65.6 \% .72 \%$ caesarean section occured in unbooked cases. $\mathrm{P}$ value is $>0.05$, which was not significant.

Table-V

Mode of delivery between booked and unbooked cases $(n=218)$

\begin{tabular}{lccccc} 
& & Vaginal Delivery & Caeserean section & Total & P value \\
\hline Booked cases & no & 51 & 82 & 133 & 0.390 \\
& $\%$ & $38.5 \%$ & $61.5 \%$ & $100 \%$ & 85 \\
UnbookedCases & no & 24 & $72.0 \%$ & $100 \%$ \\
& $\%$ & $28.0 \%$ & 143 & 218 \\
\hline Total & no & 75 & $65.6 \%$ & $100 \%$ \\
& $\%$ & $34.4 \%$ & & \\
\hline
\end{tabular}


Table-V

\begin{tabular}{|c|c|c|c|c|c|c|}
\hline \multicolumn{7}{|c|}{ Comparison of Mean( $\mathrm{Kg})$ Birthweight between booked and unbooked cases $(n=214)$} \\
\hline & No & Mean & Std. deviation & Std. Error & Mean & T test \\
\hline Booked cases & 133 & 3.02 & .477 & .077 & & 0.010 \\
\hline Unbooked cases & 81 & 2.65 & .595 & 0.121 & & \\
\hline
\end{tabular}

Among 218 cases ( 4 cases are Intra uterine death) Mean birthweight of booked and unbooked cases were $3.022 \pm .477 \mathrm{Kg}$ and $2.65 \pm .594 \mathrm{~kg}$. P value unbooked case gr $<0.05$ which is significant. All 4 cases of intrauterine death belong to unbooked case group.

Among 214 cases (4 cases IUD) 41.9\% were required referral to Neonatal unit, booked cases $25.6 \%$ and $69.6 \%$ were unbooked cases. $\mathrm{P}$ value is $<.05$, so highly significant.

Table VII

\begin{tabular}{|c|c|c|c|c|c|}
\hline \multicolumn{6}{|c|}{ Referral to neonatal Care unit among booked and unbooked cases $(n=214)$} \\
\hline & & Required Referral & Referral Not req. & Total & P value \\
\hline \multirow[t]{2}{*}{ Booked cases } & no & 34 & 99 & 133 & \\
\hline & $\%$ & $25.6 \%$ & $74.4 \%$ & $100 \%$ & \\
\hline \multirow[t]{2}{*}{ UnbookedCases } & no & 52 & 29 & 81 & \\
\hline & $\%$ & $69.6 \%$ & $30.4 \%$ & $100 \%$ & 0.61 \\
\hline \multirow[t]{2}{*}{ Total } & no & 86 & 128 & 214 & \\
\hline & $\%$ & $41.9 \%$ & $58.1 \%$ & $100 \%$ & \\
\hline
\end{tabular}

Table 8 shows the comparison of postpartum complication between booked and unbooked patients. $30.5 \%$ of unbooked cases had post-partum complication and only $16.7 \%$ of booked cases have such complication.

Table-VIII

Postpartum complications among booked and unbooked cases $(n=218)$

\begin{tabular}{|c|c|c|c|c|c|}
\hline \multirow[t]{2}{*}{ Postpartum complications } & \multicolumn{2}{|c|}{ Booked cases $\quad(n=133)$} & \multicolumn{2}{|c|}{ Unbooked cases $(n=85)$} & \multirow[t]{2}{*}{$P$ value } \\
\hline & No & $\%$ & No & $\%$ & \\
\hline Post partam haemorrhage & 9 & 6.8 & 11 & 12.9 & \\
\hline Wound infection after operation & 8 & 6.0 & 8 & 9.2 & 0.061 \\
\hline Puerperal sepsis & 6 & 3.9 & 7 & 8.4 & \\
\hline Total & 23 & 16.7 & 26 & 30.5 & \\
\hline
\end{tabular}

\section{Discussion}

Lack of access to antenatal care has been linked to increased mortality and morbidity for mother and baby. In this study, a positive correlation between unbooked mothers with adverse feto-maternal outcome was observed.

There is no doubt that the uses of maternal health services improve reproductive outcomes. ${ }^{6}$
In this study, $60.9 \%$ of patients have four or more antenatal care which is more than $31 \%$, that has been describe by Bangladesh demoghraphic and health survey ${ }^{3}$.

This is may be due to study was done in short period of time and conducted in tertiary level hospital with wellequipped Gynae and obstetric department. But 39.1\% cases are un booked .It is the reason for concern for all care providers . 
Though socio -demographic factors have association of patient having four or more antenatal care, but mean age of both this group is about $24.05 \pm 5.5$ and $25.44 \pm 5.4$, there is no significant difference between the age group. This also supported by Jaleel R, Khan A study at Pakistan ${ }^{7}$.

But Gross et $\mathrm{al}^{8}$ showed that advanced age group had more antenatal care then young age group.

In the present study the socio- economic status has no significant role among women receiving antenatal care but educational status had. This may due to number of study population. The result was not consistant with others. Fawcus SR et $\mathrm{al}^{9}$ and Chigbu B et al ${ }^{10}$, Akowuah et $\mathrm{al}^{11}$ showed that a higher percentage of unbooked mothers belonged to lower socio- economic status. The poor economic and education status may make it difficult for women to make informed decisions about using preventive and promotive health services, such as antenatal care.

In interpretation of our results, we found that unbooked mothers had adverse fetal and maternal outcome. But this study showed that the incidence of caesarean section is high between unbooked and booked mothers ( $72 \%$ vs. $61.5 \%)$. The reason behind this could be:

Many of the booked patients with complications like pregnancy induced hypertension, post caesarean status, primigravida with breech presentation attends labour room earlier and at the slightest and earlier detection of deviation from normal labour pattern undergo caesarean section.

Many of the booked patients had associated risk factors in the form of once or twice previous caesarean section, bad obstetric history, elderly primigravida not willing for vaginal birth, cephalo pelvic disproportion and contracted pelvis. Such cases were being planned for elective caesarean section but had to be taken as emergency cases as they came in early labour thereby increasing the caesarean section rate in booked mothers. The results is not consistant with Mundhra $\mathrm{R}$ et al in India ${ }^{12}$. In her study non-booked cases has lower rate of caesarean section than booked cases (28.39\% vs. $36.84 \%)$ The most important indication for $\mathrm{C} / \mathrm{S}$ in unbooked cases was prolonged labour with foetal distress followed by obstructed labour. Similar findings have been reported in a study carried out by Danish $\mathrm{N}^{13}$.

The commonest maternal morbidity observed in this study is postpartum haemorrhage. This is consistent with other studies presented internationly and locally ${ }^{7,10,9}$, their incidences being $13.9 \%{ }^{4}, 3.50 \%,{ }^{7} 15.2 \%{ }^{9}$. Frequency of postpartum hemorrhage is not far higher in unbooked patients as compared to booked patients in the study presented. This may be due to smaller sample size. The causes of PPH are prolonged labour, obstructed labour followed by atonic uterus in unbooked cases. In booked cases causes are pre natal like placenta praevia. Wound infection is found about $7.2 \%$ of unbooked which is similar with Dinesh et al ${ }^{14}$. Mean birth weights of unbooked cases are $2.65 \pm 0.595 \mathrm{~kg}$ and booked cases are $3.02 \pm 0.477$ which is much higher. Jaleel $\mathrm{R}, \mathrm{Khan}^{7}$. has shown that frequency of birth asphyxia and Low Birth Weight was significantly higher in babies of nonbooked mothers, as was the perinatal mortality rate. Lack of antenatal care was associated with higher incidence of birth asphyxia in a study in Majeed et al. ${ }^{15}$ Fatrakul et al ${ }^{16}$ has reported inappropriate antenatal care as a risk factor for hypoxic ischemic encephalopathy in newborn infants. Frequency of birth asphyxia, LBW, NICU admissions are significantly higher in unbooked mothers. No case of intrauterine fetal demise was noted in the booked group. Referral to neonatal unit is much higher in my study. This is because of prolonged labour and failed home trial. Though referral to neonatal unit about $66.4 \%$ which is similar Mundhra et $\mathrm{al}^{14}$.

\section{Limitation:}

This study was done in short period of time and conducted in tertiary level hospital with well-equipped Gynae and obstetric department. Thus the result does not reflexs whole Bangladesh secenario.

\section{Conclusion}

We conclude in our study that poor utilization of antenatal care is associated with adverse feto-maternal outcome. Antenatal care and its importance can be implemented through general and health education, developing infrastructure, transport and communication facilities. Hence, targeted, integrated, patient friendly, affordable and accessible health services in the form of Antenatal care need to be delivered in an equitable manner so as to improve the outcome for many women and children. We hope the result of this study will proved the fact that Antenatal care is an important component to ensure successful fetomaternal outcome. Our aim to motivate the health care provider to encourage the pregnant mother for regular antenatal care not only one or two but at least four ( according to WHO). Antenatal care is provided free of cost in our institutional service

\section{References}

1. WHO. Global Health Observatory (GHO) data: Neonatal Mortality.World Health Organization. 2017 http://www. who. int/ gho/ child_health/ mortality/ neonatal_text/ en/ (accessed 21 Aug 2017). 
2. Ministry of Health and Family Welfare (MOHFW) [Bangladesh]. 2011. Strategic Plan for Health, Population and Nutrition Sector Development Program (HPNSDP) 2011-2016. Dhaka, Bangladesh: MOHFW

3. National Institute of Population Research and Training (NIPORT), Mitra and Associates, and ICF International. 2013. Bangladesh Demographic and Health Survey 2014. Dhaka, Bangladesh and Calverton, Maryland, USA: NIPORT, Mitra and Associates, and ICF International.

4. UNICEF. UNICEF data: monitoring the situation of children and women. UNICEF $2017 \mathrm{https}$ // data. unicef. org/ topic/ maternal- health/antenatal- care/\# (accessed 21 Aug 2017).

5. Wang W, Alva S, Wang S, et al. Levels and trends in the use of maternal health services in developing countries. DHS comparative reports No. 26 Calverton, Maryland, USA: ICF Macro. 2011.

6. Letamo G. and Majelantle RG. 2001. Factors inûuencing low birth weight and pre-maturity in Botswana. Journal of BioSocial Science 33: 391-403

7. Jaleel R, Khan A. Obstetric morbidity in the booked versus non-booked patients - A comparative study at Lyari General Hospital.Pakistan Journal of surgery2008;36(3):196-201

8. Gross et al.: Timing of antenatal care for adolescent and adult pregnant women in south-eastern Tanzania. BMC Pregnancy and Childbirth 2012 12:16.

9. Fawcus SR, Crowther CA, Van Baelen P, Marumahoko J. Booked and Unbooked mothers delivering at Harare Maternity
Hospital, Zimbabwe: a comparison of maternal characteristics and fetal outcome. Cent Afr J Med 1992 Oct;38(10):402-8.

10. Chigbu B, Onwere S, Kamanu CI, Aluka C, Okoro O, Adibe E. Pregnancy outcome in Booked and Unbooked Mothers in South Eastern Nigeria .East Afr Med J. 2009 Jun; 86(6): 26771 .

11. Akowuah et al.: Determinants of Antenatal Healthcare Utilisation by Pregnant Women in Third Trimester in PeriUrban Ghana. Hindawi .Journal of Tropical Medicine Volume 2018, Article ID 1673517, 8 pages https://doi.org/10.1155/ 2018/1673517

12. Mundhra $\mathrm{R}$ et al. Utilization of antenatal care and its influence on fetal-maternal outcome: a tertiary care experience .Int $\mathrm{J}$ Reprod Contracept Obstet Gynecol. 2013 Dec;2(4):600-606

13. Danish N, Fawad A, Abbasi N .Assessment of pregnancy outcome in primigravida:comparison between booked and unbooked patients. J Ayub Med Coll Abbottabad 2010;22(2):22-24

14. Bang R A, Bang A T, Reddy M H, Deshmukh MD, Baitule S B, Fillipe V. Maternal morbidity during labour and the puerperium in rural homes and the need for medical attention: A prospective observational study in Gadchiroli, India. Br J Obstet Gynaecol 2004; 111: 231-238.

15. Majeed R, Memon Y, Majeed F, Shaikh N P, Rajar U D. Risk factors of birth asphyxia. J Ayub Med Coll 2007; 19(3): 6771.

16. Fatrakul S, Parisuwanna P, Thaitumyanon P. Risk factors for hypoxic-ischemic encephalopathy in asphyxiated newborn infants. J Med Assoc Thai 2006; 89(3): 322-328. 